\title{
Study on In Situ Stress Distribution Law of the Deep Mine: Taking Linyi Mining Area as an Example
}

\author{
Xuelong Li $\mathbb{D}^{1,2,3}$ Shaojie Chen $\mathbb{D D}^{1,3}$ Sheng Wang, ${ }^{1}$ Meng Zhao, ${ }^{4}$ and Hui Liu ${ }^{4}$ \\ ${ }^{1}$ Mine Disaster Prevention and Control-Ministry of State Key Laboratory Breeding Base, \\ Shandong University of Science and Technology, Qingdao 266590, Shandong, China \\ ${ }^{2}$ State Key Laboratory of Coal Resources and Safe Mining, China University of Mining and Technology, Xuzhou 221116, \\ Jiangsu, China \\ ${ }^{3}$ College of Energy and Mining Engineering, Shandong University of Science and Technology, Qingdao 266590, Shandong, China \\ ${ }^{4}$ Gucheng Coal Mine, Shandong Energy Linyi Coal Mine Group, Jining 272100, Shandong, China
}

Correspondence should be addressed to Shaojie Chen; chensj@sdust.edu.cn

Received 15 February 2021; Revised 18 March 2021; Accepted 12 April 2021; Published 21 April 2021

Academic Editor: Fengqiang Gong

Copyright (c) 2021 Xuelong Li et al. This is an open access article distributed under the Creative Commons Attribution License, which permits unrestricted use, distribution, and reproduction in any medium, provided the original work is properly cited.

The variation of the in situ stress state is closely related to various factors. In situ stress state is also an important indicator to guide mining production. The study of in situ stress measurement and its distribution characteristics has always been a basic and very important work in mine production. In this study, the deep mines of Linyi Mining Area were considered as the research object. In this regard, the stress distribution law of each mine was studied. We found that the relationship between principal stresses was $\sigma_{H}>\sigma_{v}>\sigma_{h}$, which belongs to the strike-slip stress regime. In this stress regime, the lateral Earth pressure coefficient was greater than one, and the magnitude of the three principal stresses all showed an increasing trend with the increase of depth. The maximum horizontal stress direction of the Gucheng Coal Mine, Guotun Coal Mine, and Pengzhuang Coal Mine was NW-SE under the influence of regional geological structure, while the maximum horizontal stress direction of Wanglou Coal Mine was NE-SW under the influence of local geological structure. Besides, the relationship between mine in situ stress and mine geological structure, the impact of original rock stress on stope stability, and the effect of original rock stress on floor water inrushing were also investigated. We believe that the research results are beneficial to mine disaster prevention and safety production.

\section{Introduction}

Variation of the in situ stress state is closely related to engineering geological hazards, sliding instability of crustal fracture, earthquake preparation, etc. The study of in situ stress measurement and its distribution characteristics has always been a basic and very important task in rock mechanics and geodynamics. The measured in situ stress data can not only directly reflect the characteristics of the regional in situ stress field and the distribution characteristics of the in situ stress in the engineering area but also can determine the properties of engineering rock mass for stability analysis of surrounding rock and support structure design. Moreover, the in situ stress state is also closely related to the slip instability of fault structures and earthquake preparation. In recent decades, many researchers in
China and abroad have conducted in-depth studies regarding the in situ stress state in different regions of the world based on the measured in situ stress data, making the characteristics of the in situ stress field in the shallow crust more and more clear [1].

The concept of the in situ stress was first put forward by Swiss geologist Heim, who believed that the magnitude of the vertical stress was related to the buried depth, and vertical stress was equal to horizontal stress [2]. In China, the in situ stress measurement was first introduced into geomechanics by Professor Li Siguang, and a lot of in situ stress measurement studies were carried out in the subsequent engineering practice [3]. In 1991, Meifeng conducted a systematic study on the deviation caused by temperature in in situ stress measurements and proposed a new set of 
approaches for solving this problem [4]. Since that time, China has also made many achievements in in situ stress measurement [5]. After years of development, there are a variety of in situ stress measurement methods at the present stage. Currently, the in situ stress measurement methods are mainly divided into two categories: direct method and indirect method [6]. The direct method of measurement predominantly includes the flat Jack method, hydraulic fracturing method, and acoustic emission method, while the indirect method of measurement mostly includes strain recovery method, borehole caving method, and sleeve hole stress relief method [7-11]. The stress relief method is a welldeveloped in situ stress measurement technology, which has been broadly used in recent years [12].

Geostress not only guides mine production but also plays an important role in preventing some disasters [13]. Yu Weijian studied the field investigation, laboratory test, numerical simulation, and theoretical analysis of deep chamber, and put forward a comprehensive support and repair scheme of "bolt, metal mesh, injection, grouting, anchor cable and combined anchor cable" $[14,15]$. Through the measured in situ stress data and optimization analysis, $\mathrm{Li}$ Peng et al. obtained the characteristics of in situ stress field within the measured buried depth range of metal mining areas in mainland China, which has great guiding significance for the production of metal mining areas and provides a reference for coal mining [16-19]. Based on field measurement of local stress field, rock mechanics test, threedimensional finite element numerical simulation and other methods of Cai Meifeng, the energy distribution law in the surrounding rock and the possibility of rock burst during deep mining in Linglong gold mine were analyzed, and the suggested measures for preventing and controlling rock burst were put forward [20-23]. In order to accurately detect the location of the in situ stress peak in the undeveloped area in mining, Xu Jiangtai et al. took a phosphate mine mining surface in western Henan as the background and established an overall model through ANSYS/LS-DYNA, which provided a foundation for the prevention of safety accidents caused by dynamic disasters in the mining process [24, 25]. $\mathrm{Li}$ Jing et al. studied the stress distribution law of complex fault structure area in Junggar Basin by means of the neural network, numerical simulation, fractal dimension analysis, and other methods to guide the development of local mineral resources $[26,27]$. Zongyuan Ma was studied deeply buried under the condition of high in situ stress and the complex stress intensity under the condition of the intermediate principal stress to the intact rock material static or dynamic mechanical behavior and strength characteristics analyzed the deep rock engineering in high ground stress and high speed impact additional impact the destruction mechanism of pressure and damage to large deep rock stress in the process of mining provides the theory support [28-30]. Li Peng et al. analyzed the difference of tectonic stress field between shallow and deep engineering areas by studying the measured in situ stress data of shallow and deep areas after optimized treatment, providing theoretical support for disaster prevention and mitigation in deep mining [31-34].
The exploitation and utilization of coal resources play a decisive role in promoting the rapid economic development of Shandong Province. In the process of mining, engineering dynamic disasters such as rock burst and rock burst and water inrush may occur, which is directly related to their in situ stress environment [35-39]. Therefore, it is very important to strengthen the research on regional stress accumulation level and crustal stability. To fully grasp the distribution characteristics of the current in situ stress field and stress accumulation level in Shandong, this study considered the deep mines of Linyi Mining Area in Shandong as an example to examine the correlation between the stress distribution law of a deep mine and its disaster prevention. We believe that the results of this research are of great practical significance to the exploitation of mineral resources, underground engineering construction, and disaster prevention and mitigation in this area.

\section{Testing Principle and Arrangement of Measuring Points}

2.1. Testing Principle. Stress relief method is a relatively mature technology of in situ stress measurement, and it is also the only method that can measure the in situ stress accurately and quantitatively. The basic principle of the stress relief method is that when a rock is removed from the rock mass under stress, it will expand and deform due to the elasticity of the rock [40-43]. The three-dimensional expansion deformation of the rock block after stress relief is measured, and its elastic modulus is determined by the elastic modulus rate in the field, then the magnitude and direction of the stress in the rock mass before stress relief can be calculated by the linear Hooke's law (Figure 1).

\subsection{Measuring Point Layout Principle}

(1) Measurement points should be arranged in the undisturbed area of the proposed mining area and its surrounding area

(2) The influence range of roadway excavation is generally 2-3 times the width of the roadway, and it should be arranged in the original rock stress area outside this area

(3) The original rock stress measurement points should be avoided as far as possible from the area with complex structure because the geological structure is often the place where the in situ stress is concentrated, especially the area with complex structure

(4) The layout of measuring points should consider the convenience of construction and the safety of staff

2.3. Arrangement of Measuring Points. According to the basic principle of original rock stress measuring point layout, we selected Gucheng mine, Guotun mine, Wanglou mine, and Pengzhuang mine, which belonged to Linyi Mining Area, to carry out in situ stress testing. Combined with the underground production and construction of the 
selected mines, the specific layout of measuring points in each mine was as follows:

Two measuring points were arranged in Gucheng Coal Mine. GCMC-1 (No. 1 measuring point of Gucheng Coal Mine) was located in the centralized track lane (buried depth: $1192 \mathrm{~m}$ ) of mining area 31, and GCMC-2 (No. 2 measuring point of Gucheng Coal Mine) was located in the track contact lane (buried depth: $1195 \mathrm{~m}$ ) of 3106. Four points were chosen for Guotun Coal Mine in the original rock stress measurement. GTMC-1 (No. 1 measuring point of Guotun Coal Mine) was located in a track transportation tunnel in the 1304 \# 12 traverse points outside the $40.0 \mathrm{~m}$ $(806.47 \mathrm{~m})$ buried depth. GTMC-2 (No. 2 measuring point of Guotun Coal Mine) was located at GS13 track transportation tunnel in the $1301-2$ \# wire points $(855.67 \mathrm{~m})$ buried depth. GTMC-3 (No. 3 measuring point of Guotun Coal Mine) was located in 1301\#GS4 traverse points in the track transportation tunnel in the $25.0 \mathrm{~m}(832.77 \mathrm{~m})$ buried depth, and the GTSC-4 was located in the track transportation tunnel in the 1301\#L 0 traverse points before $50.0 \mathrm{~m}$ $(842.27 \mathrm{~m})$ buried depth. In Wanglou Coal Mine, the original rock stress was measured at the escape adit of gangue bin contact roadway at the absolute depth of $933.7 \mathrm{~m}$ (WLMC-1 (No. 1 measuring point of Wanglou Coal Mine)), and the original rock stress was measured at the contact roadway of 12301 track at the absolute depth of $933.6 \mathrm{~m}$ (WLMC-2 (No. 2 measuring point of Wanglou Coal Mine)). Four points were arranged in Pengzhuang Coal Mine. PZMC-1 (No. 1 measuring point of Pengzhuang Coal Mine), PZMC-2 (No. 2 measuring point of Pengzhuang Coal Mine), and PZMC-3 (No. 3 measuring point of Pengzhuang Coal Mine), and PZMC-4 (No. 4 measuring point of Pengzhuang Coal Mine) were, respectively, arranged in the absolute depth of $735.95 \mathrm{~m}, 773.7 \mathrm{~m}, 721.5 \mathrm{~m}$, and $537.0 \mathrm{~m}$. PZMC-1 was located at 1307 along the groove on the $1500 \mathrm{~m}$, and the second point (PZMC-2) was chosen at Yu Dongyi 2 track down the mountain at the top to avoid adit. The third point (PZMC-3) was selected in 1309 under the transportation tunnel between the F16 and manhole. The fourth point (PZMC-4) was located at the bottom of the west wing tape descent.

The specific burial depth, lithology, and related rock properties of all the above observation points are shown in Table 1.

\section{The Test Results}

3.1. Type of the In Situ Stress Field. Based on forming and adjusting factors of the stress field in the base areas, the in situ stress field could be divided into the gravity stress field dominated by the gravity of rock mass, the tectonic stress field dominated by tectonic movement, and the local stress field formed by adjusting factors. Among them, the gravity stress field and tectonic stress field are the main components of the current in situ stress field. Table 2 shows that the maximum horizontal stress of the four mining areas was greater than the vertical stress. According to the type of the local stress field, the four mining areas belonged to the tectonic stress field.
Based on the three principal stress directions, the stress state of the in situ stress field could be divided into the reverse fault type stress state and strike-slip type stress state. When the magnitude of $\sigma_{H}\left(\sigma_{1}\right.$ in the table above $)>\sigma_{h}\left(\sigma_{3}\right.$ in the table above) $>\sigma_{v}$, the stress state belongs to the reverse fault regime, which is conducive to the formation and activity of the reverse fault. When the magnitude of $\sigma_{H}>\sigma_{v}>\sigma_{h}$, the stress state belongs to the strike-slip fault regime, which is conducive to the formation and activity of the strike-slip faults. Table 2 exhibits that the relationship between the magnitude of the three stresses in each mine is $\sigma_{H}>\sigma_{v}>\sigma_{h}$. Thus, all the four mines belonged to the strikeslip stress regime, which was conducive to the formation and activity of the reverse fault.

3.2. Principal Stress Varies with Depth. We measured the ground stress conditions of four coal mines in Linyi Mining Area. It can be concluded from Figure 2 that the measured data were summarized based on law regardless of the geographical position, the condition of rock lithology, geological structure, and large differences. Considering this, it can be still clearly observed that with the deepening of the buried depth, the principal stress showed a gradually rising trend.

The effect of depth on the in situ stress is largely the same as the cause of hydrostatic pressure. The weight of the overburden rocks imposes a compressive load on rock masses below, resulting in the law that vertical stress increases with the increase of the buried depth. The generation of horizontal stress is also related to the gravity of the overburden. Hence, the horizontal stress will increase with the increase of the depth. However, the geological structure is the most important factor determining the level of horizontal stress. In general, the closer the geological structure is to the surface, the greater the stress change will be. Therefore, compared with the deep strata, the horizontal stress in the shallow strata is greater than the vertical stress. However, the relationship between the overall horizontal stress and the burial depth still presents a positive correlation. Although the corresponding relationship between principal stress and buried depth may have a slight deviation under the influence of other factors, the overall regularity still shows that the principal stress increases with the increase of the buried depth. The GTMC-3 measuring point in Figure 2 was close to the fault, which influenced the ground stress around the measuring point. This caused the ground stress measured at this measuring point to be much greater than that at other measuring points with similar burial depth.

3.3. Variation Law of the Pressure Measuring Coefficient with the Depth. The lateral Earth pressure coefficient is a physical quantity used to describe the in situ stress state. It refers to the ratio of the maximum horizontal effective stress to the vertical effective stress at a certain point. Figure 3 reveals that the pressure measurement coefficient of these measuring points generally increased with the increase of the buried depth. However, there is a certain difference in the 

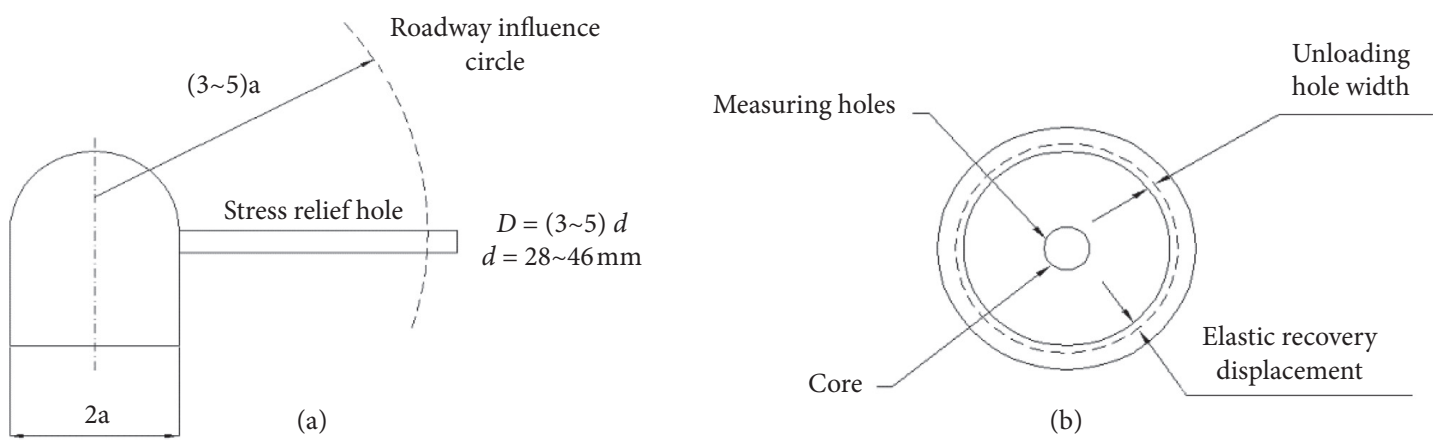

(b)

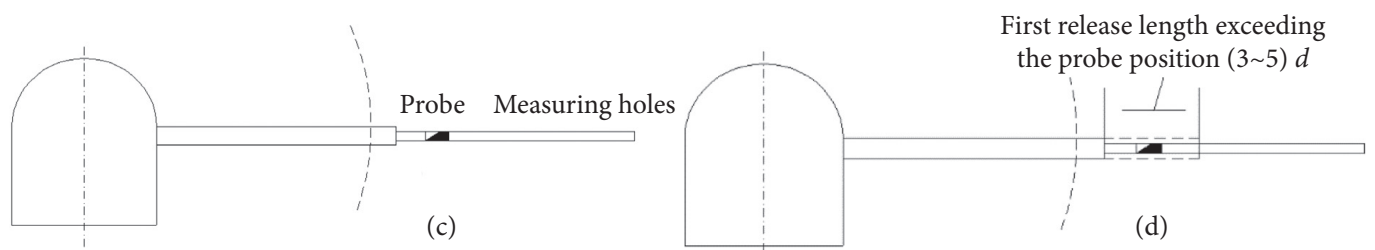

FIGURE 1: Schematic diagram of stress relief principle.

TABLE 1: Relative situation of each measurement point of in situ stress.

\begin{tabular}{lccccc}
\hline Buried & Depth $(\mathrm{m})$ & Lithologic & Compressive strength (MPa) & Elastic modulus (GPa) & Poisson ratio \\
\hline GCMC-1 & 1192 & Sandy mudstone & 29.4 & 2.07 & 2.16 \\
GCMC-2 & 1195 & Fine sandstone & 49.8 & 28.9 & 0.24 \\
GTMC-1 & 806.47 & Pebblestone & 105.0 & 19.4 & 18.2 \\
GTMC-2 & 855.67 & Pebblestone & 85.7 & 16.7 & 0.16 \\
GTMC-3 & 832.77 & Pebblestone & 67.7 & 15.4 & 0.32 \\
GTMC-4 & 842.27 & Pebblestone & 68.3 & 31.3 & 0.19 \\
WLMC-1 & 933.7 & Sand and mudstone interbedded & 32.0 & 2.79 & 0.29 \\
WLMC-2 & 933.6 & Pebblestone & 74.7 & 3.99 & 0.26 \\
PZMC-1 & 735.95 & Pebblestone & 64.2 & 2.21 \\
PZMC-2 & 773.7 & Cobblestone & 83.6 & 70.3 & 0.26 \\
PZMC-3 & 721.5 & Fine sandstone & 68.3 & 0.28 \\
PZMC-4 & 537.0 & Fine sandstone & & 2.49 \\
\hline
\end{tabular}

TABLE 2: Stress situation of each mining area.

\begin{tabular}{lccccccc}
\hline Measuring point & Depth/(m) & $\sigma_{1}(\mathrm{MPa})$ & $\sigma_{2}(\mathrm{MPa})$ & $\sigma_{3}(\mathrm{MPa})$ & $\sigma_{\mathrm{v}}(\mathrm{MPa})$ & Type of stress field & Stress state \\
\hline GCMC-1 & 1192 & 47.59 & 29.12 & 27.43 & 29.12 & Tectonic stress field & Strike-slip type \\
GCMC-2 & 1195 & 49.84 & 30.68 & 29.43 & 30.68 & Tectonic stress field & Strike-slip type \\
GTMC-2 & 855.67 & 44.17 & 24.37 & 16.88 & 24.37 & Tectonic stress field & Strike-slip type \\
GTMC-3 & 832.77 & 56.56 & 21.11 & 15.02 & 21.11 & Tectonic stress field & Strike-slip type \\
GTMC-4 & 842.27 & 31.33 & 20.64 & 17.13 & 20.64 & Tectonic stress field & Strike-slip type \\
WLMC-1 & 933.7 & 36.24 & 26.87 & 19.02 & 26.87 & Tectonic stress field & Strike-slip type \\
WLMC-2 & 933.6 & 34.53 & 28.38 & 26.64 & 28.38 & Tectonic stress field & Strike-slip type \\
PZMC-1 & 735.95 & 21.89 & 18.16 & 8.24 & 18.16 & Tectonic stress field & Strike-slip type \\
PZMC-2 & 773.7 & 26.92 & 19.22 & 17.33 & 19.22 & Tectonic stress field & Strike-slip type \\
PZMC-3 & 721.5 & 17.13 & 11.84 & 9.73 & 11.84 & Tectonic stress field & Strike-slip type \\
PZMC-4 & 537 & 15.33 & 12.89 & 7.57 & 12.89 & Tectonic stress field & Strike-slip type \\
\hline
\end{tabular}

comparison of each measuring point. These differences were primarily caused by overburden lithology, nearby geological structure, human factors, and other factors. At present, most of the investigations on lateral Earth pressure coefficient tend to believe that the lateral Earth pressure coefficient tends to be a stable value with the increase of the depth. In the shallow part of the rock layer, the tectonic stress is the main stress, and with the increase of the depth, the in situ stress gradually changes to the deep hydrostatic pressure. The depth of the four mines measured in this study was still obviously affected by geological structure. Hence, the lateral stress increased to a certain extent, which demonstrated that other factors (mostly geological structure factors) had a great influence on the in situ stress field. 


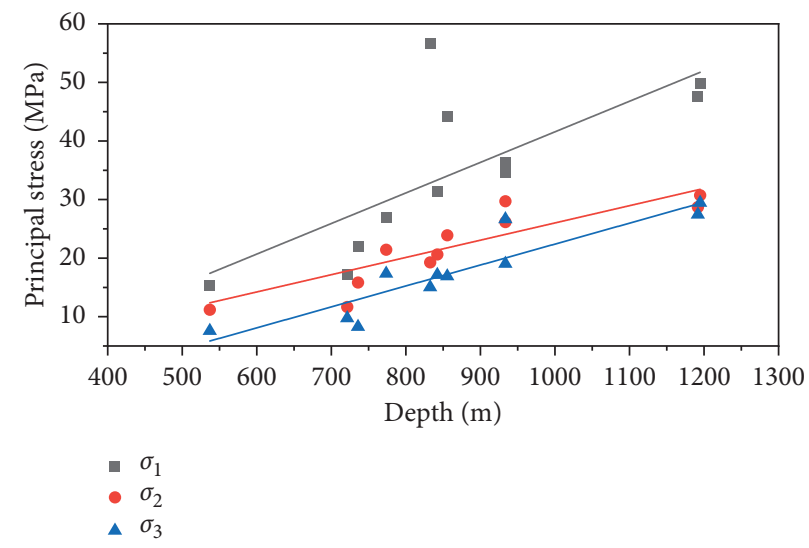

FIgURE 2: The variation of the principal stress with the depth.

3.4. Variation Law of Relative Magnitude of Horizontal Difference Stress with the Depth. Horizontal difference stress is the ratio of the difference between the maximum and minimum horizontal stresses and the sum of the maximum and minimum horizontal stresses. It can be seen from Figure 4 that the horizontal stress difference decreased slightly with the deepening of the buried depth and generally remained stable at about 0.32 . Horizontal difference stress can represent the relative magnitude of the maximum shear stress in the horizontal plane and can reflect the failure state of the crust to a certain extent by expressing the shear stress state of the crust in the region. Therefore, this parameter can also be utilized as the mechanical basis to evaluate the unstable slip of active fractures. Because this parameter was presented as a ratio, thus, it increased the discreteness of the data to some extent. However, overall it still presented a certain rule, namely the increase of the horizontal difference stress with the depth showed a moderately reduced trend and its sensitivity to the deep change was very poor. Thus, it could be thought that the relative magnitude of the horizontal difference stress was almost 0.32 , and it had little to do with the depth.

According to the existing studies, if the relative magnitude of the horizontal difference stress in the crust is more than $0.5-0.7$, it is very likely to produce shear sliding failure in the crust. Figure 4 displays that the relative magnitude of the horizontal difference stress at each measuring point of Guotun Coal Mine and Wanglou Coal Mine was within the range of 0.5-0.7. From this perspective, the shear sliding failure was likely to occur. However, whether or not the shear sliding failure will occur in these mines still depends on the natural conditions of the mine itself.

\subsection{Distribution Characteristics of the Maximum Horizontal} Principal Stress. The maximum horizontal stress is shown in Figure 5.

Figure 5 reveals that the maximum horizontal stress of Wanglou Coal Mine was distributed at about $80^{\circ} \mathrm{W}$, and the direction of the measuring points arranged in the other three coal mines was mostly within $30^{\circ} \mathrm{S}-75^{\circ} \mathrm{E}$, which was related to the geographical location of the mine. Among them, the four measuring points of Pengzhuang Coal Mine were generally smaller in terms of the maximum horizontal stress. These points were located within the range of $40^{\circ}-75^{\circ}$ south by the east direction. This was because the buried depth was shallower than other measuring points. The azimuth of the three measuring points in Guotun Coal Mine was about $60^{\circ}$ south by east direction, and the azimuth difference was very small. However, the maximum horizontal stress of these measuring points varied significantly, which was more related to the lithology and geological structure around the measuring points. The two measuring points of Gucheng Coal Mine and Pengzhuang Coal Mine were similar to each other. The magnitude difference of the maximum horizontal stress was very small, and the azimuth difference was about $10^{\circ}$.

Figure 5 shows that the main distribution direction of the maximum horizontal stress of the four mines was NW-SEE. The main factors influencing the maximum horizontal stress direction were the seismicity zone and the geological tectonic movement that was experienced in this region, and the maximum horizontal stress was generally perpendicular to the fault zone. The properties of the surrounding rock, geological structure, and mining disturbance at the measuring point would lead to the development of the local faults and then the change of the direction of the maximum horizontal stress, which led to about $10^{\circ}$ difference in the direction of the maximum horizontal stress between different measuring points in the same mine (Figure 5). In different regions or at different locations in the same region, the directions of the maximum horizontal stress are not completely consistent. This discrepancy also indicates the complexity of regional fault properties and motion modes.

\section{Discussion}

4.1. Relationship Analysis of Original Rock Stress and Mine Geological Structure. The principal stress direction is not only affected by the regional principal stress direction but also by the local geological structure. From the perspective of original rock stress direction, the four mining areas could be divided into two types for analysis, among which the maximum principal stress direction of Guotun, Gucheng, and Pengzhuang Coal Mines 


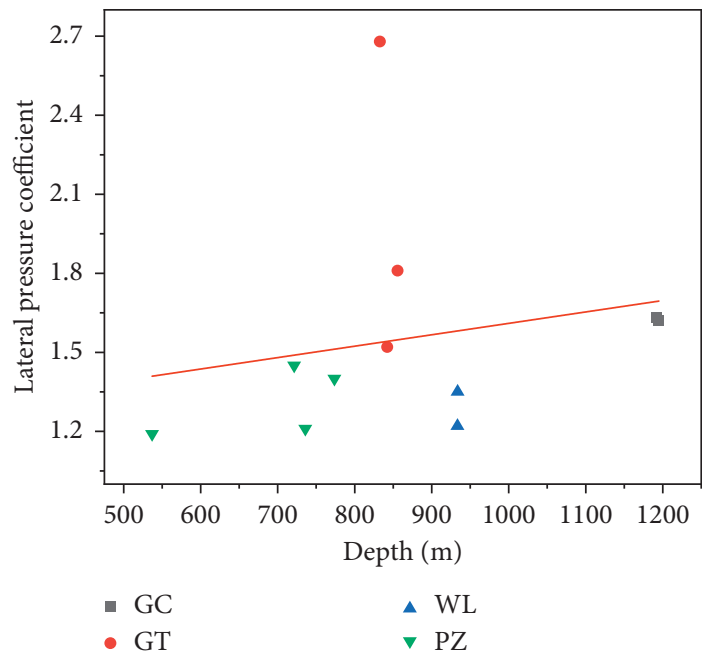

Figure 3: Variation of the pressure measuring coefficient with the depth.

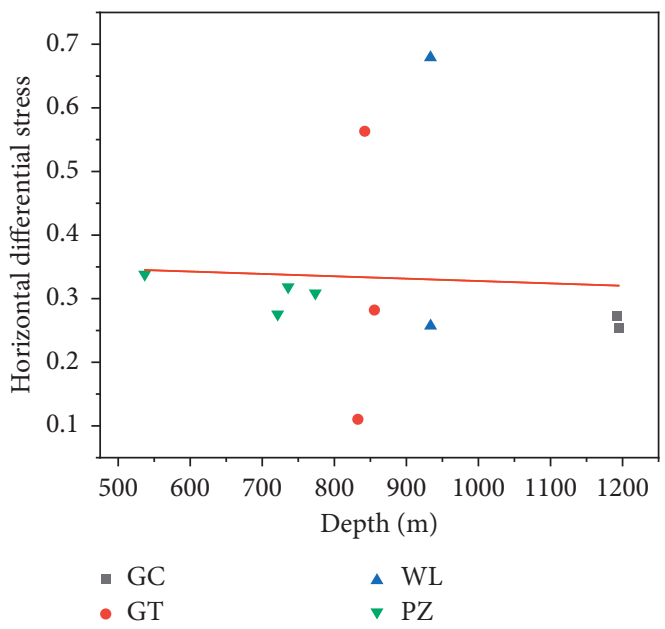

Figure 4: Relationship between the relative magnitude of horizontal difference stress and the buried depth.

was NW-SE. The maximum principal stress direction of Wanglou Coal Mine was NE-SW direction, which was predominantly controlled by regional structures such as near NEtrending faults in Jining Coalfield.

The Guotun mine field was largely controlled by the regional structure, such as the north-south fault in Juye Coalfield. Under the influence of the regional structure, the wide and slow fold was developed, accompanied by a certain number of faults. The stratum in the whole area was gentle in the west and south and steep in the north and east. The main stress direction of the mine field should be NW-SE due to the compression of the NW-SE direction. The direction of the mine main stress was also affected by the local structure of the mine field, which was a secondary factor affecting the main stress of the mine.

Wanglou Coalfield was chiefly controlled by Jining Coal inside the regional structure, such as nearly NS-trending fault fold structure development. In the southern and northern development, also a nearly east-west fault existed, and the zone with fracture structure was given a priority that was accompanied by the growth faults with a nearly NStrending fault of the field by the extrusion of the northsouthwest to east. As a result, the area of the principal stress direction of the field had to be the north-southwest to the east. The principal stress direction of the measured point was the same as that of the mine subjected to regional extrusion. Therefore, the local structure was the main factor affecting the main stress direction of the mine, and the regional structure of the mine field was a secondary factor affecting the main stress direction of the mine.

4.2. Influence Analysis of Original Rock Stress on Stope Stability. Under the condition that the maximum horizontal stress is enough to destroy the surrounding rock, the heading direction of the roadway is of great significance for maintaining the stability of the roadway [44-48]. In the case that the maximum horizontal stress is at different angles relative to the roadway, the roadway failure is shown in Figures 6 and 7. 


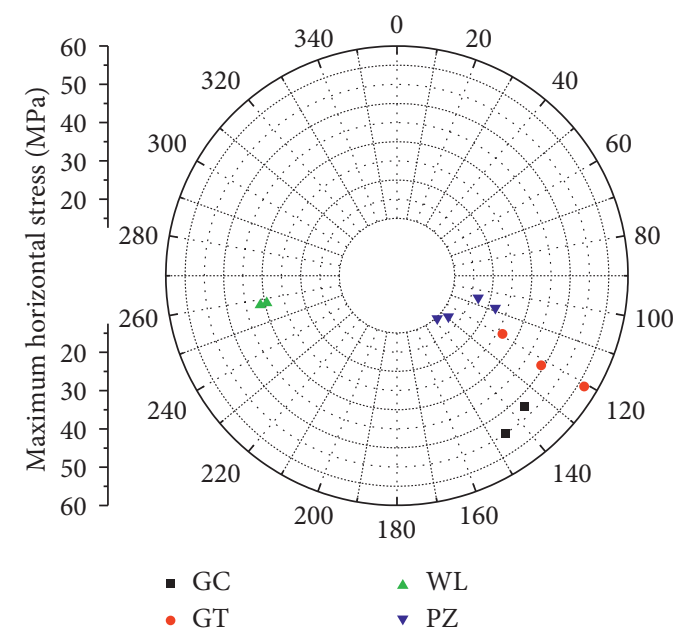

FIGURE 5: Maximum horizontal stress distribution.
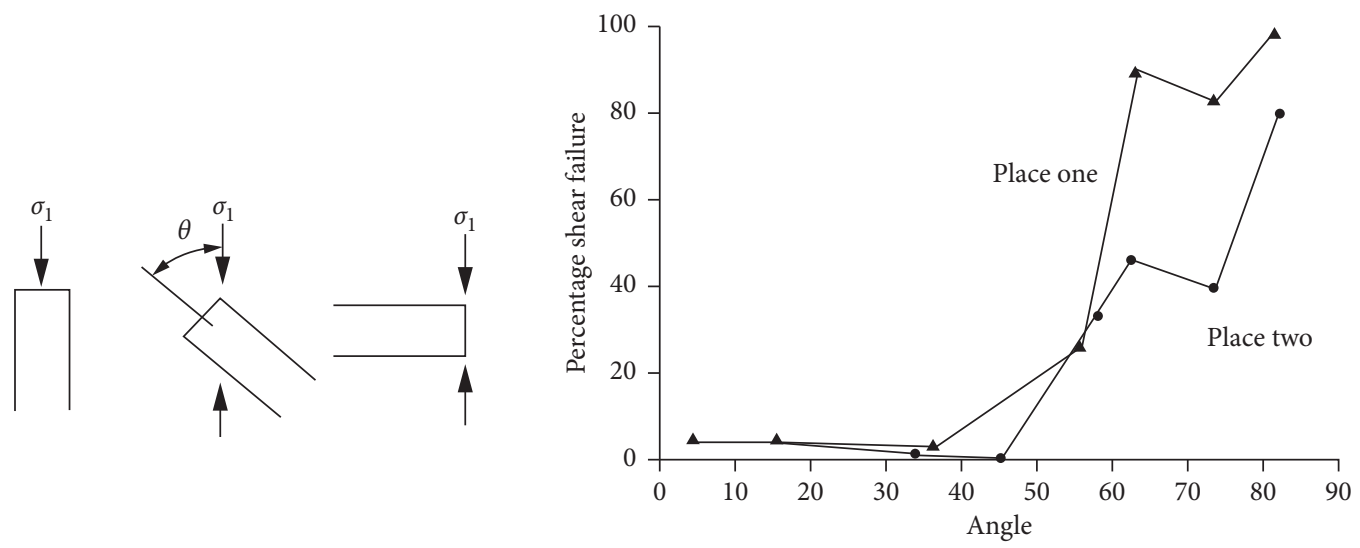

Figure 6: Roof failure at different angles relative to the maximum horizontal stress.

As can be observed from Figures 6 and 7, when the heading direction of the roadway was parallel to the maximum horizontal principal stress, the influence of the horizontal stress was the least, which was most beneficial to the stability of the roof and floor. When the heading direction was perpendicular to the maximum horizontal principal stress, the influence of the horizontal stress was the greatest, and the stability of the roof and floor was the most unfavorable. When the roadway was obtuse relative to the direction of the maximum horizontal principal stress, stress concentration appeared on one side of the roadway and stress release on the other side. Thus, the deformation and failure of the roof and floor would be biased to one side of the roadway. In the section with poor roof condition, the influence of the horizontal stress on the roadway and stope was more obvious, and the scope of roof damage caused by the horizontal stress was deepening. With the continuous expansion of the mine mining area and the increase of the buried depth, the influence of the horizontal stress on the roadway and stope will be fully noticeable. Under the action of the maximum horizontal stress, the roof and floor of the roadway will undergo shear failure, resulting in the deformation of the surrounding rock. Therefore, the bolt support design of the roadway should focus on enhancing the stability of surrounding rock at the early stage of roof deformation to control the deformation of surrounding rock at the later stage.

Under the condition that the mining area design has been completed, the heading direction of the roadway cannot be changed if the measured results of the existing measuring points show that the angle between the maximum horizontal stress direction and the heading direction is large. To ensure production safety, the deformation observation of the roadway should be strengthened in the process of tunneling, and the support strength of the roadway should be strengthened in the area of large deformation of surrounding rock. In the undeveloped area, the heading direction of the main roadway should be consistent with the direction of the maximum horizontal stress as much as possible to reduce the influence of the horizontal stress on the roadway and to avoid the deterioration of roadway condition caused by blind roadway layout in the future. 


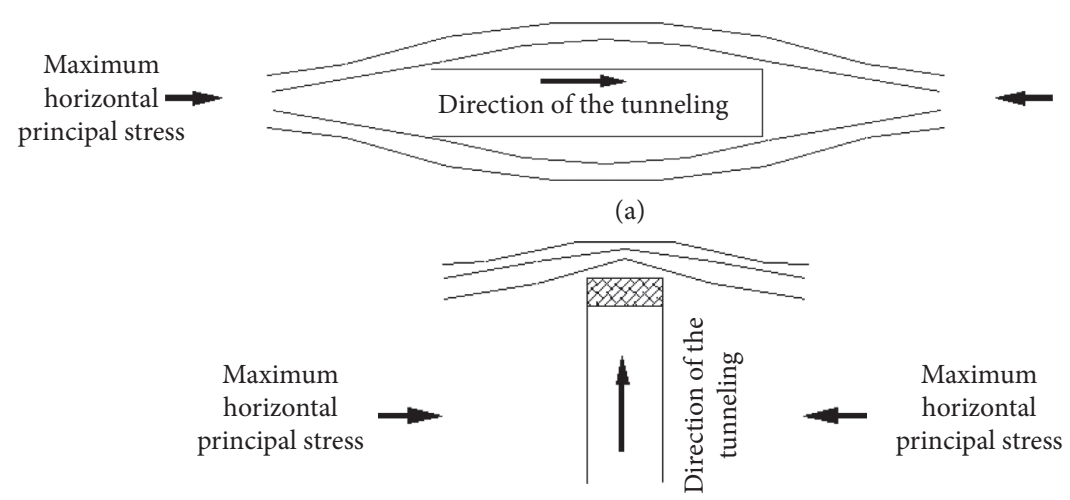

(b)

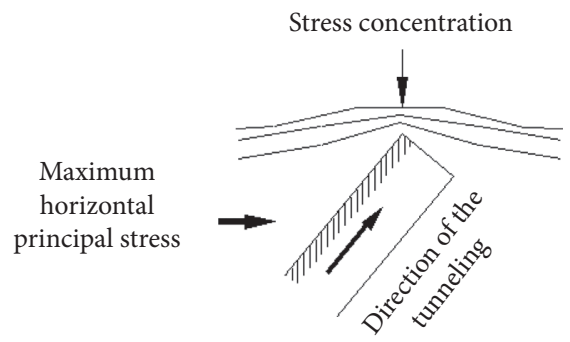

(c)

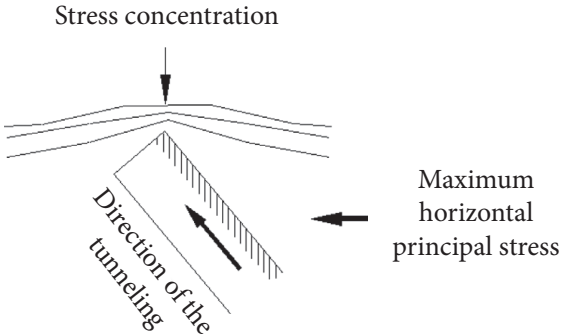

(d)

Figure 7: Difference of roadway conditions in different heading directions (plan). (a) Good roadway condition. (b) Poor roadway condition. (c) Deformation occurred on the left side of the roadway. (d) Deformation occurred on the right side of the roadway.

4.3. Analysis of Original Rock Stress and Floor Water Inrush. Under the joint action of mining pressure and aquifer water pressure, when the floor failure depth extends to the lower aquifer and the confined water pressure is greater than or equal to the minimum horizontal stress, the permeability of floor rock mass increases, and seepage occurs when the permeability increases to a certain degree. With the increase of seepage flow, the floor water inrush takes place. Many scholars and engineers in China and abroad devote their time to investigate the relationship between rock mass stress and permeability [49-53], which is only confined to indoor study. No progress has been made in the field research on the law of rock mass stress and permeability, and there is a lack of research on the original rock stress and floor failure depth. After excavation, the stress is redistributed, and the horizontal stress is transferred to the roof and floor, and hence, the horizontal stress is concentrated in the roof and floor.
Therefore, a deep displacement gauge can be installed on the floor to measure the range of floor rock failure, providing a research direction for the direct measurement of floor failure depth and laying a foundation for the study of the relationship between stress and permeability.

According to the theory of the maximum horizontal stress applied to roof and floor, floor failure is also caused by horizontal stress, which is the key factor to determine the depth of floor failure. If the layout direction of the working face along the groove is almost perpendicular to the direction of the maximum horizontal stress, the maximum horizontal stress has the most serious impact on the damage degree of the roof and floor of the roadway. This will lead to a significant reduction in the thickness of the effective waterproof layer and a considerable increase in the possibility of water inburst. Thus, when the direction of the working face along the groove is close to vertical to the maximum 
horizontal stress, the observation and monitoring of floor damage degree should be strengthened to prevent the occurrence of floor water inrush accidents.

\section{Conclusion}

For the study of the distribution rule of deep mine in situ stress and its relationship with the mine disasters, we chose the Linyi Mining Area, including Gucheng, Guotun, Wanglou, and Pengzhuang Coal Mines as the research object. We adopted the combination of the original rock stress measurement and comprehensive experimental research method and obtained the regional in situ stress distribution of deep roadway surrounding rock. The main conclusions of this study were as follows:

(1) The maximum principal stresses in the in situ stress field of the four mines were all greater than the vertical stress. Thus, the four mines belonged to the tectonic stress field in the in situ stress classification. In all four mines, we had the following relationship: $\sigma_{H}>\sigma_{v}>\sigma_{h}$ that belongs to the strike-slip stress regime in the classification of stress state, which is conducive to the formation and activity of the strikeslip faults.

(2) The lateral Earth pressure coefficients of the mines were all greater than one, and the magnitude of the three principal stresses increased with the increase of the depth. However, the relative magnitude of the horizontal difference stress diminished with the increase of the depth, but the reduction range was very small and generally remained stable at about 0.3 .

(3) The maximum horizontal stress direction of Gucheng Coal Mine, Guotun Coal Mine, and Pengzhuang Coal Mine was NW-SE, while the maximum horizontal stress direction of Wanglou Coal Mine was NE-SW. The in situ stress of Gucheng, Guotun, and Pengzhuang mining areas was primarily affected by regional geological structure, while that of Wanglou Coal Mine was predominantly affected by local structure. Hence, the direction of the maximum horizontal stress was different in these four mines.

(4) The original rock stress is affected by the geological structure and local structure. Thus, it is best to arrange the roadway along the direction of the maximum horizontal stress. The horizontal stress is the key factor to determine the failure depth of the floor. When the direction of the working face along the groove is nearly perpendicular to the maximum horizontal stress, the monitoring of the failure degree of the roof and floor should be strengthened, and appropriate support should be installed.

\section{Data Availability}

The data used to support the findings of this study are available from the corresponding author upon request.

\section{Conflicts of Interest}

The authors declare that they have no conflicts of interest.

\section{Acknowledgments}

This work was supported by the National Natural Science Foundation of China (51904167, 51474134 and 51774194), Taishan Scholars Project, Taishan Scholar Talent Team Support Plan for Advantaged and Unique Discipline Areas, State Key Laboratory of Coal Resources and Mine Safety of China (SKLCRSM19KF008), Natural Science Foundation of Chongqing, China (cstc2019jcyj-bsh0041), Postdoctoral Science Foundation Project Funded by State Key Laboratory of Coal Mine Disaster Dynamics and Control (2011DA105287-BH201903), and Key R\&D Plan of Shandong Province (2019SDZY034-2).

\section{References}

[1] P. Li, Q. Guo, H. T. Liu et al., "Characteristics of current insitu stress field and stress accumulation in Shandong region," Chinese Journal of Rock Mechanics and Engineering, vol. 36, no. 9, pp. 2220-2231, 2017.

[2] Z. Arno and S. Ove, Stress Field of the Earth's Crust, Springer, no. 01, p. 01, Dordrecht, Netherlands, 2010.

[3] F. R. Xie, Q. C. Chen, X. F. Cui et al., Crustal Stress in china, Geological Publishing House, Beijing, China, 2003.

[4] M. F. Cai, "Studies of temperature compensation techniques in rock stress measurements," Chinese Journal of Rock Mechanics and Engineering, vol. 10, no. 3, pp. 227-235, 1991.

[5] Y. H. Zhang, Study on In-Situ Stress Measurement Method Considering Non-linear Elasticity of Rock Mass in Deep, University of Science and Technology Beijing, Beijing, China, 2020.

[6] T. X. Chen, Research on In-Situ Stress Measurement and Application Based on Inelastic Strain Recovery, Yanshan University, Qinhuangdao, China, 2020.

[7] J. Zhang, L. Si, J. Chen, M. Kizil, C. Wang, and Z. Chen, "Stimulation techniques of coalbed methane reservoirs," Geofluids, vol. 2020, no. 3, 23 pages, 2020.

[8] Z. Yu, J. Wen, Q. Zhu, H. Ma, and Y. Feng, "A combined denoising method for microseismic signals from coal seam hydraulic fracturing: multithreshold wavelet packet transform and improved hilbert-huang transform," Shock and Vibration, vol. 2021, 15 pages, 2021.

[9] S. J. Chen, Z. W. Du, and Z. Zhang, "Effects of chloride on the early mechanical properties and microstructure of ganguecemented paste backfill," Construction and Building Materials, vol. 235, Article ID 117504, 2020

[10] Z. X. Yu, F. X. Jiang, and L. F. Wang, "Experiment to improve accuracy of borehole stressmeter to monitor and measure coal and rock stress," Coal Science and Technology, vol. 38, no. 11, pp. 53-55+92, 2010.

[11] J. W. Du and W. S. Hu, "Application of wireless stress meter in high stress mining roadway," Coal, vol. 27, no. 11, p. $33+54$, 2018.

[12] M. F. Cai, "Review of principles and methods for rock stress measurement," Chinese Journal of Rock Mechanics and Engineering, vol. 12, no. 3, pp. 275-283, 1993.

[13] M. F. Cai, Rock Mechanics and Engineering, Science Press, Beijing, China, 2013. 
[14] W. Yu and K. Li, "Deformation mechanism and control technology of surrounding rock in the deep-buried large-span chamber," Geofluids, vol. 2020, 22 pages, 2020.

[15] W. Yu, B. Pan, F. Zhang, S. Yao, and F. Liu, "Deformation characteristics and determination of optimum supporting time of alteration rock mass in deep mine," KSCE Journal of Civil Engineering, vol. 23, no. 11, pp. 4921-4932, 2019.

[16] P. Li and S. J. Miao, "Analysis and application of in-situ stress in metal mining area of Chinese mainland," Chinese Journal of Engineering, vol. 39, no. 3, pp. 323-334, 2017.

[17] M. F. Cai, C. Z. Chen, H. Peng et al., "In-situ stress measurement by hydraulic fracturing technique in deep position of Wanfu Coal Mine," Chinese Journal of Rock Mechanics and Engineering, vol. 25, no. 5, pp. 1069-1074, 2006.

[18] J. Fan, W. Liu, D. Jiang, J. Chen, W. N. Tiedeu, and J. J. K. Daemen, “Time interval effect in triaxial discontinuous cyclic compression tests and simulations for the residual stress in rock salt," Rock Mechanics and Rock Engineering, vol. 53, no. 9, pp. 4061-4076, 2020.

[19] H. P. Xie, F. Gao, and Y. Ju, "Research and development of rock me-chanics in deep ground engineering," Chinese Journal of Rock Mechanics and Engineering, vol. 34, no. 11, p. 2161, 2015.

[20] M. F. Cai, W. D. Liu, and Y. Li, "In-situ stress measurement at deep position of linglong gold mine and distribution law of insitu stress field in mine area," Chinese Journal of Rock Mechanics and Engineering, vol. 29, no. 2, pp. 227-233, 2010.

[21] H. P. Kang, B. D. Yi, F. Q. Gao et al., "Datebase and characteristics of underground in-situ stress distribution in Chinese coal mines," J China Coal Soc, vol. 44, no. 1, pp. 23-33, 2019.

[22] F. Fan, X. B. Li, J. Rostami et al., "Numerical investigation of hard rock strength and fracturing under polyaxial compression based on Mogi-Coulomb failure criterion," International Journal of Geomechanics, vol. 19, no. 4, Article ID 04019005, 2019.

[23] M. F. Cai, D. Ji, and Q. F. Guo, "Study of rockburst prediction based on in-situ stress measurement and theory of energy accumulation caused by mining disturbance," Chinese Journal of Rock Mechanics and Engineering, vol. 32, no. 10, pp. 1973-1980, 2013.

[24] J. T. Xv and Z. W. Yang, "Study on in-situ stress of phosphate rock mining based on ANSYS/LS-DYNA," Mining Research and Development, vol. 41, no. 2, pp. 25-28, 2021.

[25] J. J. Feng, E. Y. Wang, Q. S. Huang et al., "Study on coal fractography under dynamic impact loading based on multifractal method," Fractals, vol. 28, no. 1, Article ID 2050006, 2020.

[26] J. Li, C. Liu, H. M. Liu et al., "Distribution and influencing factors of in-situ stress in complex fault tectonic region," Journal of China University of Mining \& Technology, vol. 50, no. 1, pp. 123-137, 2021.

[27] Q. L. Zou, H. Liu, Y. J. Zhang et al., "Rationality evaluation of production deployment of outburst-prone coal mines: a case study of nantong coal mine in Chongqing, China," Safety Science, vol. 122, Article ID 104515, 2020.

[28] Z. Ma, F. Dang, Y. Li et al., "Influence of geostress field on dynamic mechanical behavior of intact rock," Arabian Journal of Geosciences, vol. 14, no. 2, p. 78, 2021.

[29] X. Li, S. Chen, E. Wang, and Z. Li, "Rockburst mechanism in coal rock with structural surface and the microseismic (MS) and electromagnetic radiation (EMR) response," Engineering Failure Analysis, vol. 124, no. 6, Article ID 105396, 2021.
[30] B. Kong, Z. Liu, and Q. G. Yao, "Study on the electromagnetic spectrum characteristics of underground coal fire hazardous and the detection criteria of high temperature anomaly area," Environmental Earth Sciences, vol. 80, no. 3, pp. 1-11, 2021.

[31] P. Li, F. Q. Guo, S. J. Miao et al., "Comparisons of in-situ stress fields and stability of faults in shallow and deep engineering areas," Journal of Harbin Institute of Technology, vol. 49, no. 9, pp. 10-16, 2017.

[32] X. G. Kong, S. G. Li, E. Y. Wang et al., "Dynamics behaviour of gas-bearing coal subjected to SHPB tests," Composite Structures, vol. 256, Article ID 113088, 2021.

[33] X. Hao, Y. Wei, K. Yang et al., "Anisotropy of crack initiation strength and damage strength of coal reservoirs," Petroleum Exploration and Development, vol. 48, no. 1, pp. 243-255, 2021.

[34] L. P. Li, C. S. Shang, K. W. Chu et al., "Large-scale geomechanical model tests for stability assessment of super-large cross-section tunnel," Tunnelling and Underground Space Technology, vol. 109, Article ID 103756, 2021.

[35] G. Iabichino, M. Isaia, and M. Barbero, "Development of a software for the interpretation of data obtained by CSIRO cell," Geoingegneria Ambientale Mineraria, vol. 142, no. 2, pp. 55-59, 2014.

[36] X. Li, Z. Cao, and Y. Xu, "Characteristics and trends of coal mine safety development," Energy Sources, Part A: Recovery, Utilization, and Environmental Effects, vol. 11, 9 pages, 2020.

[37] X. Hao, W. Du, Y. Zhao et al., "Dynamic tensile behaviour and crack propagation of coal under coupled static-dynamic loading," International Journal of Mining Science and Technology, vol. 30, no. 5, pp. 659-668, 2020.

[38] R. Zhang, J. Liu, and Z. Y. Sa, "Fractal characteristics of acoustic emission of gas-bearing coal subjected to true triaxial loading," Measurement, vol. 169, Article ID 108349, 2020.

[39] S. Liu, X. Li, D. Wang, and D. Zhang, "Experimental study on temperature response of different ranks of coal to liquid nitrogen soaking," Natural Resources Research, vol. 30, no. 2, pp. 1467-1480, 2021.

[40] A. Tsuji, S. Zhang, T. Hashimoto, S. Okano, T. Shobu, and M. Mochizuki, "In-situ measurement of transitional stress in welds metal of steel using synchrotron radiation," Journal of the Society of Materials Science, Japan, vol. 65, no. 9, pp. 665-671, 2016.

[41] X. Liu, D. Song, X. He, Z. Wang, M. Zeng, and L. Wang, "Quantitative analysis of coal nanopore characteristics using atomic force microscopy," Powder Technology, vol. 346, pp. 332-340, 2019.

[42] L. Qin, S. G. Li, C. Zhai et al., "Changes in the pore structure of lignite after repeated cycles of liquid nitrogen freezing as determined by nitrogen adsorption and mercury intrusion," Fuel, vol. 267, Article ID 117214, 2020.

[43] W. Shen, G. Shi, M. Wang et al., "Method of entry layout under synergistic effects of abutment stress and dynamic stress," Shock and Vibration, vol. 2020, 16 pages, 2020.

[44] C. L. Zhang, E. Y. Wang, J. Xu et al., "A new method for coal and gas outburst prediction and prevention based on the fragmentation of ejected coal," Fuel, vol. 287, Article ID 119493, 2021.

[45] K. Wang and F. Du, "Coal-gas compound dynamic disasters in China: a review," Process Safety and Environmental Protection, vol. 133, pp. 1-17, 2020.

[46] X. Ge and M. Hou, "Principle of in-situ 3D rock stress measurement with borehole wall stress relief method and its preliminary applications to determination of in-situ rock stress orientation and magnitude in Jinping hydropower 
station," Science China Technological Sciences, vol. 55, no. 4, pp. 939-949, 2012.

[47] K. Wang, P. Yang, G. Yu, C. Yang, and L. Zhu, "3D Numerical modelling of tailings dam breach run out flow over complex terrain: a multidisciplinary procedure," Water, vol. 12, no. 9, Article ID 2538, 2020.

[48] Y. C. Xue, W. B. Sun, and Q. S. Wu, "The influence of magmatic rock thickness on fracture and instability law of mining surrounding rock," Geomechanics and Engineering, vol. 20 , no. 6 , pp. $547-556,2020$.

[49] D. Sun, Q. Chen, A. W. Li et al., "Anelastic strain recovery in situ stress measurement method and its application prospect in underground mines," IOP Conference Series Earth and Environmental Science, vol. 570, Article ID 042021, 2020.

[50] F. Zhou, W. B. Sun, J. L. Shao et al., "Experimental study on nano silica modified cement base grouting reinforcement materials," Geomechanics and Engineering, vol. 20, no. 1, pp. 67-73, 2020.

[51] Q. Niu, J. Pan, Y. Jin et al., "Fractal study of adsorption-pores in pulverized coals with various metamorphism degrees using N2 adsorption, X-ray scattering and image analysis methods," Journal of Petroleum Science and Engineering, vol. 176, pp. 584-593, 2019.

[52] Q. Zou, H. Liu, Z. Cheng, T. Zhang, and B. Lin, "Effect of slot inclination angle and borehole-slot ratio on mechanical property of pre-cracked coal: implications for ECBM recovery using hydraulic slotting," Natural Resources Research, vol. 29, no. 3, pp. 1705-1729, 2020

[53] J. Q. Weng, L. B. Zeng, W. Y. Lv et al., "Width of stress disturbed zone near fault and its influencing factors," Journal of Geomechanics, vol. 26, no. 1, pp. 39-47, 2020. 